\title{
Overview of guidelines for the management of dyslipidemia: EU perspectives
}

This article was published in the following Dove Press journal:

Vascular Health and Risk Management

6 September 2016

Number of times this article has been viewed

\section{Vicente Giner-Galvañ ${ }^{\prime}$ María José Esteban-Giner Vicente Pallarés-Carratalá2,3 \\ 'Department of General Internal Medicine, Unit of Hypertension and Cardiometabolic Risk, Hospital Mare de Déu dels Lliris, Alcoy, Alicante, ${ }^{2}$ Department of Health Surveillance, Unión de Mutuas, Castellón de la Plana, ${ }^{3}$ Department of Medicine, Universitat Jaume I, Castellón, Spain}

Correspondence: Vicente Giner-Galvañ Department of General Internal Medicine, Unit of Hypertension and Cardiometabolic Risk, Hospital Mare de Déu dels Lliris, Polígono de Caramanxel $\mathrm{s} / \mathrm{n}, 03804$, Alcoy, Alicante, Spain Tel +34965 537400

Fax +34966528 867

Email giner_vicgal@gva.es
Abstract: Modern medicine is characterized by a continuous genesis of evidence making it very difficult to translate the latest findings into a better clinical practice. Clinical practice guidelines (CPG) emerge to provide clinicians evidence-based recommendations for their daily clinical practice. However, the high number of existing CPG as well as the usual differences in the given recommendations usually increases the clinician's confusion and doubts. It has apparently been the case for the 2013 American College of Cardiology/American Heart Association (ACC/AHA) Guideline on the Treatment of Blood Cholesterol. These CPG proposed new and controversial concepts that have usually been considered an antagonist shift respective to European CPG. The most controversial published proposals are: 1) to consider evidence just from randomized clinical trials, 2) creation of a new cardiovascular (CV) risk calculator, 3 ) to consider reducing $\mathrm{CV}$ risk instead of reducing low-density lipoprotein cholesterol (LDLc) as the target of the treatment, and 4) consideration of statins as the only drugs for treatment. A deep analysis of the 2013 American College of Cardiology/American Heart Association CPG and comparison with the European ones show that from a practical and clinical point of view, there are more similarities than differences. To further help clinicians in their daily work, in the present globalized world, it is time to discuss and adopt a mutually agreed upon document created by both sides of the Atlantic. Probably it is not a short-term solution. Meanwhile, taking advantage of the similarities, the recommended practical attitude for the daily clinical practice should be based on 1) early detection of people with increased CV risk promoting the use of validated local scales, 2) reinforce the mainstream importance of nonpharmacological treatment, and 3) need for periodically monitoring response with analytical parameters (LDL or non-highdensity lipoprotein cholesterol) and global CV risk estimation. Technological solutions such as the big data technology could help to obtain high-quality evidence in an intermediate term. Keywords: dyslipidemia, statins, cardiovascular risk, clinical practice guidelines

\section{Introduction}

The ultimate objective of the clinician is to apply the best evidence to his/her daily clinical practice, but some difficulties hinder this. Because modern medicine is in a continuous evolution due to the increasing amount of new evidence, it is quite difficult for clinical physicians to remain up-to-date. When consulting some expert opinions in order to clarify doubts, the opinion as well as the potential applicability of the same data varies depending on the consulted publication. Because trials study specific populations in specific scenarios, it is not unusual for physicians to find that the problem to be clarified has never been studied or that the existing evidence is too weak to establish a clear recommendation. ${ }^{1,2}$ 
Applying evidence-based medicine principles, ${ }^{3}$ clinical practice guidelines (CPG) try to solve the aforementioned problems. They are the written result of reviewing the evidence to translate it to daily clinical practice to guide physicians in making decisions based on the best available evidence. However, this is not always the case as can be demonstrated by the unjustified high number of existing $\mathrm{CPG},{ }^{4}$ each with different recommendations. For example, currently in the United States, there are more than 2,500 CPG. ${ }^{5}$ On the other hand, different studies have demonstrated low quality, ${ }^{6-8}$ as illustrated for example by Ferket et al,${ }^{6}$ in whose manuscript, after initial consideration of nearly 1,900 CPG, only 17 of the 27 finally included were considered with "considerable rigor."

Part of the proliferation of CPG could be explained by the existence of interests outside the strictly scientific and health care fields. This is a complex element to analyze, because the majority of CPG have little information regarding conflict of interests. About three-fifths of the existing US CPG are issued by a medical society or a professional association, which leads to negative concerns regarding conflict of interests and criteria for the election of experts. ${ }^{5,7,8}$ In the previously mentioned manuscript by Ferket et al, ${ }^{6}$ only 16 of the 27 CPG included reported authors' conflicts of interest. Another factor to be considered and corrected to explain the high number of existing CPG and the high heterogeneity in their final recommendations is related to industry pressure as well as the medical scientific associations who needs to be present in the media. ${ }^{9}$

To solve this situation, different potential solutions exist. ${ }^{10}$ Some authors think that the solution is to use just the best available evidence, which in their opinion is that obtained from randomized clinical trials (RCTs). But the generalization of the results from RCT, is difficult and always needs an important subjective component of interpretation. ${ }^{4,10} \mathrm{~A}$ direct application can also be harmful because CPG do not present recommendations in terms of benefits, harms, and costs, but just in terms of efficacy and almost exclusively referred to pharmacological treatments. As recognized by evidence-based medicine itself, a wider point of view is necessary by including all kinds of information as the only way to give reasonable answers to clinical questions. ${ }^{4,5}$ This is the reason why in recent years it has been widely recognized that it is necessary to incorporate other variables apart from efficacy, such as patients' preferences and hopes in the socalled shared decision making. ${ }^{11}$ As recognized by all recent CPG, understanding the limitations of available evidence and awareness of additional published guidelines will help practitioners make personalized decisions with patients and enhance the clinician-patient discussion..$^{12,13}$

The publication of the so-called Adult Treatment Panel (ATP) IV was longtime overdue by general physicians as an actualization of the previous guideline in 2002; probably the most worldwide used CPG on dyslipidemia. ${ }^{14}$ This document has advocated for new concepts for the management of dyslipidemia, promoting some controversy. ${ }^{13}$ Since its publication, a lot of different arguments have been published against and in favor of these new concepts. In general, the new 2013 American College of Cardiology/American Heart Association (ACC/AHA) $\mathrm{CPG}^{15}$ have been considered antagonistic when compared with the European $\mathrm{CPG}^{16-18}$ points of view.

In the present review, the new ACC/AHA guidelines ${ }^{15}$ are compared with the "European" ones, considering those published by the European Society of Cardiology/European Atherosclerosis Society (ESC/EAS) in 2011 and 2012 $2^{16,17}$ and those by the British National Institute for Health and Care Excellence (NICE),${ }^{18}$ because of some differences with the ESC/EAS points of view as well as its worldwide recognition. First, those considered the most important controversial points among the new American and the European guidelines are analyzed. In the second part, those points that could be considered as consensual are also analyzed. Finally, some potential realistic actions are proposed to contribute to the reduction of actual discrepancies among CPG and the secondary confusion among clinical physicians. All the analyses and comments are made from a practical point of view trying to answer clinical daily questions.

\section{Dissimilarities}

On November 12, 2013, the ACC/AHA issued new clinical guidelines on cardiovascular (CV) disease risk assessment ${ }^{19}$ and cholesterol management. ${ }^{15}$ Since its presentation, a great controversy has emerged because these $\mathrm{CPG}$ proposals have represented a shift in the management of dyslipidemia. ${ }^{20,21}$ In the medical literature, the reactions have usually been negative when compared with other CPG, not only from the United States, ${ }^{22}$ but also from other countries and regions of the world, ${ }^{23}$ especially when considering the ESC/EAS guidelines. ${ }^{24}$ However, most recent publications recognize the limitations and gaps of the new American guidelines, ${ }^{25}$ reinforce the similarities, and propose some potential solutions to achieve a consensus. ${ }^{26,27}$

Methodological differences can explain a great part of the dissimilarities. The main methodological difference is that 2013 ACC/AHA guidelines solely consider RCT as a valid source of evidence. ${ }^{15,22}$ On the contrary, both the ESC/EAS ${ }^{16,17}$ 
and the $\mathrm{NICE}{ }^{18} \mathrm{CPG}$ consider that other sources need to be included as the only way to translate evidence to clinical practice. ${ }^{28}$ The ESC/EAS ${ }^{16,17}$ also indicates the possibility of evidence obtained from an RCT to be considered as having low quality, as well as the possibility of evidence other than RCT-obtained evidence to create a high strength recommendation because of the methodological quality of the study or its congruency with the general knowledge. In accordance with this approach, the International Atherosclerosis Society (IAS) $\mathrm{CPG}^{29}$ say that "allowing RCTs to dominate guideline development largely restricts them to drug recommendations; reliable RCTs for lifestyle therapies are few ... finally, RCTs are mostly sponsored by the pharmacological industry. They are designed primarily to obtain regulatory registration, not to answer critical questions in clinical intervention. The IAS panel recognized the enormous fund of useful information provided by RCT; but it also has placed RCT in the context of epidemiological and genetic findings." Although it has been underscored as a main dissimilarity that $\mathrm{ACC} / \mathrm{AHA} \mathrm{CPG}^{15}$ consider RCT as the only source of qualified evidence, when reinforcing the cornerstone importance of nonpharmacological treatment, these guidelines recognize that evidence is very scarce and based only on surrogate outcomes.

Another methodological limitation for all the CPG considering the recommendations obtained from RCT are that they critically depend on which publications are considered. It is obvious the effect of only just including publications since 1995 by the ACC/AHA guideline ${ }^{30}$, while the European ones include those since the sixties. ${ }^{16-18}$ This can also be applied related to the recent publication of Improved Reduction of Outcomes: Vytorin Efficacy International Trial (IMPROVE-IT), ${ }^{31}$ and Prevención con Dieta Mediterránea (PREDIMED), ${ }^{32}$ two recent big RCTs that give new evidence to be considered for all CPG on dyslipidemia but are not included in any because both the studies have been published later. In the same way, each CPG has its own criteria to select the source of evidence. Finally, although they all establish the strength of the recommendations according to the GRADE system, ${ }^{33}$ the final expression of the recommendations is not the same, contributing to the actual confusion of the clinicians. This is quite similar for the ACC/AHA ${ }^{15}$ and ESC/EAS ${ }^{16,17}$ guidelines; meanwhile the recommendations in the $\mathrm{NICE}^{18}$ CPG are expressed with the words "offer" and "consider."

The second main dissimilarity is referred to the definition of the persons in primary prevention to be treated. For the identification of patients at risk, all the actual CPG use multifactorial CV estimators (Table 1). The new ACC/AHA guidelines ${ }^{15}$ have proposed a new Pooled Cohort Equations
Risk Calculator (PCERC) based on seven major National Heart, Lung, and Blood Institute-funded cohort studies for US population to predict 10-year risk of nonfatal myocardial infarction, fatal coronary heart disease, and nonfatal or fatal stroke. ${ }^{19,34}$ Both the ESC/EAS ${ }^{16,17}$ and the NICE ${ }^{18}$ guidelines have their own calculator: the so-called Systematic Coronary Risk Evaluation Project (SCORE) ${ }^{36}$ and the QRISK2. ${ }^{37,38}$ A difference with the QRISK2 calculator, obtained from electronic health records of general practice attendees in the United Kingdom, is that the other two have been obtained from European and American cohorts of prospective studies. For all the calculators, the risk factors considered are the traditional ones (sex, blood pressure, age, smoking, and lipids), and all are estimators of absolute risk, although the $2012 \mathrm{ESC} / \mathrm{EAS}$ has a specific tool for younger people to estimate relative risk. ${ }^{16}$ In this respect, all the CPGs comment on the necessity to estimate all-life risk instead of the actual usual period of 10 years, and, as previously proposed by the IAS, ${ }^{29}$ in 2010 a version of the QRISK2 calculator estimating all-life CV risk was published. ${ }^{38}$

The main criticism to be made when analyzing the PCERC is that overestimates about $75 \%-150 \%$ the individual $\mathrm{CV}$ risk. This overestimation can be due to the inclusion of stroke as well as the adoption of a lower threshold for the definition of increased risk (7.5\% instead of $10 \%) .{ }^{45}$ The immediate consequence is the increase in the number of people to be treated. ${ }^{46,47}$ Compared with the ATP III $\mathrm{CPG},{ }^{14}$ the new guideline would increase the number of US adults eligible for statin therapy from $37.5 \%$ to $48.6 \%$. When applying PCERC for primary prevention in people at the ages 60-75 years, the percentage to be treated increases from $30.4 \%$ to $87.4 \%$ among men and from $21.2 \%$ to $53.6 \%$ among women, with the main determinant of increased risk being hypertension. ${ }^{46}$ When PCERC is applied to European populations, there is a similar impact (Table 2). ${ }^{47}$ An evident explanation for the increase is that US population has a higher CV risk than European, but it would not explain the difference when applying ATP III calculator, ${ }^{14}$ pointing to the fact that probably the incremental effect is a consequence of the lower threshold in PCERC. The "global population statinization" derived by the application of the PCERC has two immediate consequences. First, a marked economic impact, although in the opinion of the authors of the ACC/AHA CPG, ${ }^{15}$ this could be balanced by an incremental use of generic statins. In this respect, it is interesting to know that $\mathrm{ESC} / \mathrm{EAS}^{16,17} \mathrm{CPG}$ do not analyze the economic impact of their recommendations and that only for the NICE guidelines ${ }^{18}$ this aspect is considered in 
Table I Main actual disposable CV risk calculators and their general characteristics

\begin{tabular}{|c|c|c|c|c|c|c|c|}
\hline & PCERC 19 & Frmingh $^{35}$ & SCORE $^{36}$ & QRISK2 ${ }^{37,38}$ & ASSIGN $^{39}$ & Lloyd-Jones ${ }^{40}$ & PROCAM $^{41}$ \\
\hline$\overline{\text { CPG }}$ & $2013 \mathrm{ACA} / \mathrm{AHA}^{15}$ & ATP III ${ }^{14}$ & ESC/EAS $^{15,16}$ & $\mathrm{NICE}^{18}$ & $\mathrm{SIGN}^{43}$ & $\mathrm{IAS}^{29}$ & ITFPCD $^{44}$ \\
\hline Data source & $\begin{array}{l}7 \mathrm{NHLBI} \text {-funded } \\
\text { cohort studies for } \\
\text { US population }\end{array}$ & $\begin{array}{l}\text { Prospective } \\
\text { Framingham } \\
\text { Heart and } \\
\text { Offspring } \\
\text { studies }\end{array}$ & $\begin{array}{l}\text { I } 2 \text { pooled } \\
\text { prospective } \\
\text { studies from } \\
\text { II European } \\
\text { countries }\end{array}$ & $\begin{array}{l}\text { QResearch } \\
\text { electronic database }\end{array}$ & $\begin{array}{l}\text { SHHEC } \\
\text { prospective study }\end{array}$ & $\begin{array}{l}\text { Framingham Heart } \\
\text { Study participants free } \\
\text { of CV disease }\end{array}$ & $\begin{array}{l}\text { Prospective } \\
\text { study }\end{array}$ \\
\hline Population & $\begin{array}{l}\text { African-American } \\
\text { or White } \\
\text { participants with } \\
\geq 12 \text { years of } \\
\text { follow-up }\end{array}$ & $\begin{array}{l}\text { US general } \\
\text { population } \\
\text { volunteers } \\
\text { from } \\
\text { Framingham, } \\
\text { MA, USA }\end{array}$ & $\begin{array}{l}\text { Random samples } \\
\text { from general } \\
\text { population, some } \\
\text { occupational } \\
\text { cohorts }\end{array}$ & $\begin{array}{l}\text { Health records of } \\
\text { general practice } \\
\text { attendees }\end{array}$ & $\begin{array}{l}\text { General population } \\
\text { in Scottish } \\
\text { MONICA and the } \\
\text { Scottish Heart } \\
\text { Health studies }\end{array}$ & $\begin{array}{l}\text { US general population } \\
\text { volunteers from } \\
\text { Framingham, MA, USA }\end{array}$ & $\begin{array}{l}\text { Healthy male } \\
\text { employees } \\
\text { in Münster } \\
\text { (Germany) }\end{array}$ \\
\hline Sample size & $\begin{array}{l}\text { Whites: } \\
9,098 \sigma^{7} \\
\text { II,240 } 9 \\
\text { African-American: } \\
\text { I,647 o } \\
2,641 \%\end{array}$ & $\begin{array}{l}3,969 \sigma^{7} \\
4,522 \text { }\end{array}$ & $\begin{array}{l}117,098 \sigma^{7} \\
88,080 \%\end{array}$ & $\begin{array}{l}2.29 \text { million } \\
\text { (QRISK2) }\end{array}$ & $\begin{array}{l}6,540 \circ^{\prime} \\
6,757 \stackrel{9}{ }\end{array}$ & $\begin{array}{l}564 \circ^{7} \\
4,362 \text { }\end{array}$ & $\begin{array}{l}18,460 \sigma^{7} \\
8,515 \%\end{array}$ \\
\hline Age (years) & $40-79$ & $30-75$ & $40-65$ & $35-74$ & $30-74$ & 50 & $20-75$ \\
\hline Calculates & $\begin{array}{l}\text { Sex- and race- } \\
\text { specific I0-year } \\
\text { risk for fatal CHD, } \\
\text { nonfatal MI, all } \\
\text { stroke }\end{array}$ & $\begin{array}{l}\text { Latest version: } \\
\text { I0-year risk of } \\
\text { CV events }\end{array}$ & $\begin{array}{l}\text { I0-year risk of CV } \\
\text { mortality } \\
\text { Version for } \\
\text { relative risk for } \\
<40 \text { years }\end{array}$ & $\begin{array}{l}\text { I0-year risk of CV } \\
\text { events } \\
\text { All-life CV risk } \\
\text { version }^{38}\end{array}$ & $\begin{array}{l}\text { 10-year risk of CV } \\
\text { events }\end{array}$ & $\begin{array}{l}\text { Total CV morbidity by } \\
\text { age } 80 \text { years, from age } \\
50 \text { years }\end{array}$ & $\begin{array}{l}\text { I0-year risk } \\
\text { of coronary } \\
\text { and cerebral } \\
\text { ischemic } \\
\text { events }\end{array}$ \\
\hline $\begin{array}{l}\text { Included } \\
\text { variables }\end{array}$ & $\begin{array}{l}\text { Age, Tc, HDLc, } \\
\text { SBP, DM, current } \\
\text { smoking status }\end{array}$ & $\begin{array}{l}\text { Sex, age, Tc, } \\
\text { HDLc, SBP, } \\
\text { smoking, DM, } \\
\text { HTd }\end{array}$ & $\begin{array}{l}\text { Sex, age, Tc or } \\
\text { Tc/HDLc, SBP, } \\
\text { smoking } \\
\text { Versions for } \\
\text { high- and low-risk } \\
\text { countries }\end{array}$ & $\begin{array}{l}\text { Sex, age, Tc/HDLc, } \\
\text { SBP, smoking, DM, } \\
\text { social deprivation, } \\
\text { family history, BMI, } \\
\text { HTd, ethnicity, } \\
\text { comorbidity }\end{array}$ & $\begin{array}{l}\text { Sex, age, Tc, HDLc, } \\
\text { SBP, number of } \\
\text { cigarettes, DM, } \\
\text { social deprivation, } \\
\text { family history of } \\
\text { CHD }\end{array}$ & Tc, smoking, BP, DM & $\begin{array}{l}\text { Age, sex, } \\
\text { LDLc, } \\
\text { HDLc, DM, } \\
\text { smoking, SBP }\end{array}$ \\
\hline Thresholds & $\begin{array}{l}+<5 \% \\
++5-7.4 \% \\
+++\geq 7.5 \%\end{array}$ & $\begin{array}{l}+<5 \% \\
++5-20 \% \\
+++>20 \%\end{array}$ & $\begin{array}{l}+<1 \% \\
++1-4 \% \\
+++5-10 \% \\
++++>10 \%\end{array}$ & $\begin{array}{l}+5 \% \\
++10 \% \\
++15 \% \\
++++20 \%\end{array}$ & $\begin{array}{l}+<10 \% \\
++10-19 \% \\
+++\geq 20 \%\end{array}$ & $\begin{array}{l}+<15 \% \\
++15-29 \% \\
++30-44 \% \\
++++>45 \%\end{array}$ & $\begin{array}{l}+++>53 \\
(>20 \%)\end{array}$ \\
\hline
\end{tabular}

Notes: +, low CV risk; ++, moderate CV risk; +++, high CV risk; ++++, very high CV risk. Data based on Cooney et al. ${ }^{44}$

Abbreviations: ACA/AHA, American College of Cardiology/American Heart Association; ASSIGN, Assessing cardiovascular risk using SIGN guidelines to ASSIGN preventive treatment; ATP III, Adult Treatment Panel III; BMI, Body mass index; BP, blood pressure; CHD, coronary heart disease; DM, diabetes mellitus; ESC/EAS, European Society of Cardiology/European Atherosclerosis Society; Frmingh, Framingham score; HDLc, high-density lipoprotein cholesterol; HTd, having antihypertensive drugs; IAS, International Atherosclerosis Society; ITFPCD, International Task Force for Prevention of Coronary Disease; MI, myocardial infarction; NICE, National Institute for Health and Care Excellence; PCERC, Pooled Cohort Equations Risk Calculator; SBP, systolic blood pressure; SCORE, Systematic Coronary Risk Evaluation; SHHEC, Scottish Heart Health Extended Cohort; SIGN, Scottish Intercollegiate Guidelines Network; Tc, Total cholesterol; CV, cardiovascular; LDLc, low-density lipoprotein cholesterol; CPG, clinical practice guidelines; NHLB, National Heart, Lung, and Blood Institute; MONICA, multinational monitoring of trends and determinants in cardiovascular disease.

Table 2 Proportion of participants of the Rotterdam study to be treated with statins applying different actual guidelines for the management of dyslipidemia criteria

\begin{tabular}{lll}
\hline Guideline & $\delta^{\pi}$ & $q$ \\
\hline 2013 ACC/AHA ${ }^{15}$ & $96.4 \%$ & $65.8 \%$ \\
& $(95 \% \mathrm{Cl}, 95.4 \%-97.1 \%)$ & $(95 \% \mathrm{Cl}, 63.8 \%-67.7 \%)$ \\
& $\mathrm{n}=1,825$ & $\mathrm{n}=1,523$ \\
$2012 \mathrm{ESC}_{\text {EAS }} 16,17$ & $66.1 \%$ & $39.1 \%$ \\
& $(95 \% \mathrm{Cl}, 64.0 \%-68.3 \%)$ & $(95 \% \mathrm{Cl}, 37.1 \%-41.2 \%)$ \\
2002 ATP III $^{14}$ & $\mathrm{n}=1,253$ & $\mathrm{n}=906$ \\
& $52.0 \%$ & $35.5 \%$ \\
& $(95 \% \mathrm{Cl}, 49.8 \%-54.3 \%)$ & $(95 \% \mathrm{Cl}, 33.5 \%-37.5 \%)$ \\
& $\mathrm{n}=985$ & $\mathrm{n}=82 \mathrm{I}$ \\
\hline
\end{tabular}

Note: Data from Kavousi et al. ${ }^{47}$

Abbreviations: ACC, American College of Cardiology; AHA, American Heart Association; ATP, Adult Treatment Panel; $\mathrm{Cl}$, confidence interval; EAS, European Atherosclerosis Society; ESC, European Society of Cardiology. a specific and detailed way, concluding that the disposable information is very scarce to analyze the effectiveness of dyslipidemia management, although enough to establish that the cost-effective treatments are atorvastatin 20 and 80 $\mathrm{mg}$ /day for primary and secondary prevention, respectively. The second consequence of a generalized use of statins is the increased risk for toxicity. It is an important issue considering that the most important increase in adult population to be treated affects older people, with higher susceptibility for secondarisms and a considerable portion of indications in the absence of hyperlipidemia. ${ }^{48}$ However, some authors argue that the higher sensitivity of PCERC allows to cover more adequately those patients who will have a CV event, because of its better predictive capacity. ${ }^{49}$ 
The third and fourth main dissimilarities are the target of the treatment and the drugs to be used. Although the published idea is about striking change in these paradigms, when a deep analysis is made the differences are not as striking. Regarding the differences considering CV risk calculators, it has been argued that they can be mainly explained by methodological causes. When considering the target of treatment and drugs to be used, probably the dissimilarities are more dependent on the interpretation of the evidence made by each CPG.

In accordance with ATP III, ${ }^{14} \mathrm{ESC} \mathrm{EAS}^{16,17}$ and NICE ${ }^{18}$ consider that the objectives of the treatment of dyslipidemia are analytical values, the so-called, "the lower the better" strategy. The main argument by the European CPG in favor of the use of low-density lipoprotein cholesterol (LDLc) as the target of treatment are the meta-analysis by the Cholesterol Treatment Trialists' (CTT) Collaboration, ${ }^{50,51}$ estimating a direct relationship in which every $40 \mathrm{mg} / \mathrm{dL}$ reduction in LDLc is associated with a $22 \%$ reduction in $\mathrm{CV}$ events. The new ACC/AHA ${ }^{15}$ guidelines, based on the fact that any RCT has been designed to compare the effect on $\mathrm{CV}$ events of different analytical parameters to be achieved and the effect on different groups of population depending on its $\mathrm{CV}$ risk, propose that the objective of the treatment has to be just the reduction of $\mathrm{CV}$ risk itself. ${ }^{52}$

Some differences exist about which analytical parameter to use for target, although all the CPGs recognize the pathophysiological leading paper of LDLc. All of them also recognize the higher predictive capacity of apoB and the estimated non-high-density lipoprotein cholesterol (nHDLc). For the ESC/EAS ${ }^{16,17}$ as well as for ATP III ${ }^{14} \mathrm{CPG}, \mathrm{LDLc}$ is the target, based not only on the existing RCT, but also on epidemiological and experimental evidence. ${ }^{53}$ For ESC/EAS, ${ }^{16,17}$ when considering nHDLc as a target for treatment, more robust evidence is necessary, and apoB is not usually as available as the other analytical parameters. NICE guidelines ${ }^{18}$ advocate for the use of nHDLc because it includes all lipoproteins with atherogenic potential. For those CPG in favor of analytical parameters as the target of treatment, the value to be reached is always dependent on the global CV risk. A recent extensive meta-analysis about optimal strategy for monitoring lipids has found an increased prognostic value of composite parameters like total cholesterol (Tc)/HDLc ratio (HR [hazard ratio] 1.25; 95\% confidence interval [CI] 1.15-1.35) or nHDLc, compared with single parameters such as LDLc. ${ }^{54}$

For ACC/AHA CPG, ${ }^{15}$ a practical reason to defend that the objective of the treatment is reducing $\mathrm{CV}$ risk instead of an analytical parameter is that with this strategy the management of dyslipidemia will be easier for the clinician and cheaper for the health system, because periodical analytical determinations are not necessary. However, from a daily clinical practice point of view, although the intention of the analytical determinations is different from a conceptual point of view, finally the clinician will probably determine the same number of analysis because the new American $\mathrm{CPG}^{15}$ also establish the convenience of periodical analysis to be sure that the predicted reduction in LDLc in a specific patient has been reached, and also to improve the pharmacological compliance. Finally, we have to read cautiously the new American guidelines and their recommendations about analytical parameters as target of the treatment: "The Expert Panel makes no recommendations for or against specific LDLc or nHDLc targets for the primary or secondary prevention of ASCVD (atherosclerotic cardiovascular disease)." When grading the recommendation, for ACC/AHA CPG, ${ }^{15}$ "No recommendation" means "There is insufficient evidence or evidence is unclear or conflicting. Net benefit is unclear. Balance of benefits and harms cannot be determined because of no evidence, insufficient evidence, unclear evidence, or conflicting evidence, and the Work Group thought no recommendation should be".

The actual situation about dyslipidemia and treatment target can be summarized by representing both the ESC/ EAS $^{16,17}$ and the new American guidelines in two opposite positions. ${ }^{15}$ One position is the so-called "LDLc hypothesis" that defends that the benefit of the treatment of dyslipidemia is proportional to the value of plasmatic LDLc achieved ("The lower the better"). On the contrary, the so-called statin pleiotropic effects defends that the benefit obtained in major RCTs with pharmacological treatment of dyslipidemia is independent of the values of plasmatic LDLc achieved, but dependent on the pleiotropic effects of the statins. ${ }^{55}$ As previously commented, the first hypothesis is mainly supported by a meta-analysis accepted by all the guidelines although with different interpretations, that of the CTT collaborators. ${ }^{50} \mathrm{This}$ is the position of $\mathrm{NICE}^{18}$ as well as ESC guidelines. ${ }^{16,17,54} \mathrm{On}$ the contrary, ACA/AHA guidelines are based on the concept of statins as CV-risk lowering drugs due to their pleiotropic effects. ${ }^{15,50,52,55}$ In addition to previously commented reasons in this review, this point of view is supported by the absence of reduction of $\mathrm{CV}$ events when similar decreases of LDLc have been achieved with hypolipemiant drugs other than statins. ${ }^{56-58}$ The benefit obtained in RCTs like the Heart Protection Study (HPS) demonstrating the beneficial effect of treating patients with acute coronary syndrome with LDLc below $100 \mathrm{mg} / \mathrm{dL}$ with statins, is well known. ${ }^{59}$ 
Some authors have also argued that considering LDLc as the objective of the treatment can be a strategy to promote the use of new drugs. ${ }^{60}$ The recent publication of IMPROVE$\mathrm{IT}^{31}$ has reactivated the debate, ${ }^{58}$ with no clear accordance in the interpretation among the experts and medical societies. This RCT has demonstrated that the addition of ezetimibe to simvastatin after an acute coronary syndrome achieved $2 \%$ lower incidence of CV morbidity after lowering LDLc with the combination ( 69.5 vs $53.7 \mathrm{mg} / \mathrm{dL}$ ), findings consistent with the reduction estimated by statins according to the CTT meta-analysis. ${ }^{50,51}$ Although these results seem to reinforce the "LDLc hypothesis", the finding that higher reduction in high-sensitive C-reactive protein was also observed with the combination can also be interpreted in favor of an increased pleiotropic effect.

The fourth main dissimilarity is about the use of hypolipemiant drugs other than statins. All the CPG agree that statins are the first-line drugs for primary and secondary prevention, with striking differences when considering the use of other drugs. The ACC/AHA authors, ${ }^{15}$ taking into account the absence of evidence about a beneficial effect on $\mathrm{CV}$ morbidity or mortality of nonstatin hypolipemiant drugs in the scarce number of specific RCT, only consider their use in those individuals "... who are candidates for statin treatment but are completely intolerant." The ESC/EAS ${ }^{16,17}$ always recommends the use of statins, and when a high dose is not tolerated or LDLc goals are not achieved, the combination with fibrates or ezetimibe. ${ }^{61}$ All the $\mathrm{CPG}$ on dyslipidemia were published before the publication of the IMPROVE-IT results. ${ }^{32}$ However, based on the benefits obtained in subjects with aortic stenosis in the Simvastatin and Ezetimibe in Aortic Stenosis $^{62}$ study and in patients with chronic kidney disease in the Study of Heart and Renal Protection, ${ }^{63}$ the authors of ESC/ EAS $^{16,17}$ CPG consider this drug for treatment in combination with statins. For these guidelines, bile acid sequestrants have also demonstrated their efficacy in RCT with a benefit proportional to the LDLc-lowering effect but a lower tolerability. On the contrary, although we do not have an official opinion by the authors of the ACC/AHA guidelines ${ }^{15}$ about the use of ezetimibe, in a review of the evidence made by a group of experts of the US Food and Drug Administration in December $2015,{ }^{64}$ to consider its authorization for secondary prevention in combination with simvastatin, they establish that there is a lack of data after the analysis of Ezetimibe and Simvastatin in Hypercholesterolemia Enhances Atherosclerosis Regression, ${ }^{65}$ Simvastatin and Ezetimibe in Aortic Stenosis, ${ }^{66}$ and Study of Heart and Renal Protection ${ }^{63}$ RCTs. The different interpretation and derived recommendations of the same evidence related to ezetimibe can be explained by the fact that the American guidelines ${ }^{15}$ only analyze the impact on $\mathrm{CV}$ events, meanwhile the European $\mathrm{CPG}^{16,17}$ also consider the effect on LDLc. Finally, NICE guidelines ${ }^{18}$ have an intermediate position concluding that "gemfibrozil to be cost effective compared to placebo for secondary prevention in men with low HDL cholesterol and low LDL cholesterol, based on the VA-HIT (Veterans Affairs High-Density Lipoprotein Intervention Trial) study. ${ }^{66 "}$ However, when compared to statins, this effectiveness disappears due to the higher cost and higher incidence of secondarisms. NICE ${ }^{18}$ recommends, "Do not routinely offer ... except for people with metabolic syndrome with high Triglycerides (Tg) and low HDLc even if treated with a statin." For the rest of hypolipemiants data are scarcer on efficacy and economic impact, with a higher incidence of secondary effects than with statins, justifying the general recommendation of "Do not offer." When considering the use of ezetimibe, NICE has published a specific document ${ }^{67}$ recommending its use in nonfamilial heterozygous primary hypercholesterolemia when the reduction of $\mathrm{CV}$ risk is indicated, when analytical objectives are not reached, or when statins are not tolerated.

\section{Similarities}

Published commentaries about the new ACC/AHA CPG ${ }^{20}$ have usually been to underscore the controversy and dissimilarities when compared with other CPG not only in medical press but also in the general press, creating an unjustified sensationalism evident when a deep read is made in which similarities are more than dissimilarities. In any case, in modern medicine, new points of view should be not to create controversy but rational discussion. ${ }^{68}$

Some similarities have been previously mentioned in the present review: 1) admitting some limitations, to assure the highest level of evidence it is better to have data from RCTs; 2) because of the limitations of direct application of evidence obtained from RCT, it is necessary to share our doubts and opinions with the patient as a way to also ameliorate accomplishment according to the so-called shared decision making ${ }^{11}$; 3) the reinforcement of the nonpharmacological measures as the cornerstone for the treatment of dyslipidemia although there is not strong evidence for this recommendation except with PREDIMED ${ }^{32}$; 4) management based on the idea of $\mathrm{CV}$ global risk considering not just one CV risk factor but the interaction among all present in each patient; and 5) statins as the first-line drugs.

In reference to the use of multiple CV risk factor strategy, all the CPG recognize that although this strategy has 
biological plausibility, there is not any evidence about its superiority compared with that based on the treatment of individual $\mathrm{CV}$ risk factors except that obtained from some estimations, as that of Jackson et al. ${ }^{69}$ This group calculated that the number needed to prevent one $\mathrm{CV}$ event in five years when using three preventive interventions (aspirin, lipid lowering, and blood pressure lowering) was only six in the very-high-risk group compared with 36 in the low-risk group. A recent meta-analysis of the Blood Pressure Lowering Treatment Trialists' Collaboration also established a greater impact of blood pressure treatment depending on the global $\mathrm{CV}$ risk. ${ }^{70}$ Of course, the Steno experience with diabetic people is probably the most demonstrative study about the utility of this multifactorial approach. ${ }^{71}$

Referred to estimators of individual CV risk, all the guidelines are confident in the limitation of the actual calculators, with a poor predictive power, proposing the consideration of other individual variables for clinical decisions (Table 3). Although limited predictive capacity of the $\mathrm{CV}$ risk calculators is critical when evaluating patients in primary prevention, it is not the case for secondary prevention, with total accordance among all the CPG in that all people in this situation must be treated without estimating CV risk.

The main concordance, in fact unanimity, among CPG on dyslipidemia is about which must be the first-line option for pharmacological treatment: statins. All the guidelines are also in accordance with that the factor to choose which specific statin to be used is its efficacy, classifying them in those with high $(>40 \%-50 \%$ reduction of pretreatment LDLc levels), moderate (30\%-40\% reduction), and low intensity ( $<30 \%$ reduction). Those with high intensity have to be used in patients who need a higher individual $\mathrm{CV}$ risk to be lowered or lower LDLc/nHDLc levels to be achieved as a consequence of a higher individual CV risk. As shown in Table 4, although there is no absolute concordance when classifying statins by their efficacy, there are no huge differences among guidelines. This classification is almost identical for ACC/AHA ${ }^{15}$ and NICE. ${ }^{18}$ As a small difference, the $\mathrm{ESC} \mathrm{EAS}^{16,17}$ represents in a graphic the percentual decrease in LDLc expected to be achieved for each statin and dose, without a categorical classification. The differences in the classification of statins by the three

Table 3 Risk factors to be considered for the assessment of final individual CV risk in addition to CV calculators based on traditional CV risk factors

\begin{tabular}{|c|c|}
\hline Guidelines & Other $\mathrm{CV}$ risk factors to be considered for the estimation of individual global CV risk \\
\hline 2012 ESC/EAS ${ }^{16,17}$ & $\begin{array}{l}\text { - Familial prevalence of ASCVD or of major risk factors before } 55 \text { years in } 0^{7} \text { and } 65 \text { years in } 9 \\
\text { - Low socioeconomic status, lack of social support, stress at work and in family life, depression, anxiety, hostility, and the } \\
\text { type D personality } \\
\text { - DM } \\
\text { - Low HDLc or apolipoprotein AI } \\
\text { - Increased Tg, fibrinogen, homocysteine, apolipoprotein B, and lipoprotein(a), familial hypercholesterolemia or increased } \\
\text { hs-CRP } \\
\text { - Asymptomatic individuals with preclinical evidence of ASCVD (plaques or increased CIMT) } \\
\text { - Those with impaired renal function (low estimated glomerular filtration and/or increased microalbuminuria/proteinuria) } \\
\text { - Risk may be lower than indicated in those with very high HDLc levels or a family history of longevity }\end{array}$ \\
\hline 2013 ACC/AHA ${ }^{15}$ & $\begin{array}{l}\text { - Family history of premature ASCVD with onset }<55 \text { years of age in a first-degree male relative or }<65 \text { years of age in a } \\
\text { first-degree female relative } \\
\text { - Primary LDLc } \geq 160 \mathrm{mg} / \mathrm{dL} \text { or other evidence of genetic hyperlipidemias } \\
\text { - hs-CRP } \geq 2 \mathrm{mg} / \mathrm{L} \\
\text { - CAC score } \geq 300 \text { Agatston units or } \geq 75 \text { th percentile for age, sex, and ethnicity } \\
\text { - Ankle-brachial index }<0.9 \\
\text { - Lifetime risk of ASCVD }\end{array}$ \\
\hline $2014 \mathrm{NICE}^{18}$ & $\begin{array}{l}\text { - Family history of premature CV disease in medical records } \\
\text { - Familial hypercholesterolemia or other inherited disorders of lipid metabolism } \\
\text { - Low socioeconomic status } \\
\text { - Ethnicity } \\
\text { - Evidence of estimated glomerular filtration rate }<60 \mathrm{~mL} / \mathrm{min} / 1.73 \mathrm{~m}^{2} \text { and } / \text { or albuminuria } \\
\text { - People with treated HIV, serious mental health problems, taking drugs that can cause dyslipidemia (antipsychotics, } \\
\text { corticosteroids, or immunosuppressants), systemic inflammatory disorders such as systemic lupus erythematosus, on } \\
\text { antihypertensives or lipid modifying drugs, recently stopped smoking, body mass index }>40 \mathrm{~kg} / \mathrm{m}^{2} \\
\text { - People aged } 85 \text { years or older, particularly people who smoke or have raised blood pressure }\end{array}$ \\
\hline
\end{tabular}

Abbreviations: ASCVD, atherosclerotic cardiovascular disease; CAC, coronary artery calcium; CIMT, carotid intima/media thickness; DM, diabetes mellitus; HDLc, high-density lipoprotein cholesterol; HIV, human immunodeficiency virus; hs-CRP, high-sensitivity C-reactive protein; Tg, triglycerides; CV, cardiovascular; LDLc, lowdensity lipoprotein cholesterol; ESC/ EAS, European Society of Cardiology/European Atherosclerosis Society; ACC/AHA, American College of Cardiology/American Heart Association; NICE, National Institute for Health and Care Excellence. 
Table 4 Classification of statins depending on their theoretical capacity to reduce LDLc plasmatic levels

\begin{tabular}{|c|c|c|c|}
\hline Guideline & Low intensity & Medium intensity & High intensity \\
\hline 2013 ACCIAHA & $<30 \%$ & $30 \%-49 \%$ & $\geq 50 \%$ \\
\hline \multirow[t]{5}{*}{2010 CCT meta-analysis ${ }^{50,51}$} & LDLc reduction & LDLc reduction & LDLc reduction \\
\hline & FI 20-40, Lo 20 & FI 40 bid, FI XL 80, & At -80 \\
\hline & $\operatorname{Pr} 10-20$, Si 10, Pi I & $\operatorname{Pr}$ 40-80, Lo 40, & Ro $20-40$ \\
\hline & & Si $20-40$, At $10-20$, & \\
\hline & & Ro 5-10, Pi 2-4 & \\
\hline 2012 ESC/EAS & $20 \%-30 \%$ & $30 \%-40 \%$ & $>40 \%$ \\
\hline 2010 Weng et al meta-analysis ${ }^{72}$ and & LDLc reduction & LDLc reduction & LDLc reduction \\
\hline \multirow[t]{2}{*}{ Mukhtar et $\mathrm{al}^{73}$} & Fl 40, Pr 20-40, & FI 80, Lo 40-80, & At 40, Ro 40, \\
\hline & Lo $10-20$, Si 10 & Si 20, At 10, Pi I & $\mathrm{Pi} 2-4$ \\
\hline 2014 NICE $^{18}$ & $20 \%-30 \%$ & $31 \%-40 \%$ & $>40 \%$ \\
\hline \multirow[t]{3}{*}{2003 Law et al meta-analysis $^{74}$} & LDLc reduction & LDLc reduction & LDLc reduction \\
\hline & $\operatorname{Pr} 40, \mathrm{Fl}$ 40, $\operatorname{Pr} 20$ & Si 40, Si 20 , & Si 80, At 40-80, \\
\hline & FI 20, Pr 10, Si 10 & At 10 , Ro 5 & Ro $20-40$, Ro $10-20$ \\
\hline
\end{tabular}

Note: The number after the abbreviation indicates the daily dose in $\mathrm{mg}$.

Abbreviations: At, Atorvastatin; CCT, Cholesterol Treatment Trialists' Collaboration; Fl, Fluvastatin; Lo, Lovastatin; Pi, Pitavastatin; Pr, Pravastatin; Ro, Rosuvastatin; Si, Simvastatin; CV, cardiovascular; LDLc, low-density lipoprotein cholesterol; XL, extended release.

CPG can be explained because of the different bibliography used by each one. ${ }^{50,72-74} \mathrm{NICE}^{18}$ is the only guideline to also consider the effectiveness as a criterion to choose the statin to be used, concluding that atorvastatin 20 and $80 \mathrm{mg} /$ day are the options to be used in primary and secondary prevention, respectively.

Referring to the use of statins, all the guidelines, after recognizing the paucity of good studies specifically analyzing the safety, are also in agreement that main secondary effects (myopathy, hepatitis, and diabetes) have a slightly increased incidence compared with placebo, ${ }^{48}$ with a benefit clearly higher than the potential harms, with systematic reviews finding that the incidence is really unknown, with few cases occurring in large-scale RCTs and being encouraging about the safety of long-term lipid-lowering therapy. ${ }^{75,76}$ There is also general accordance in the necessity of basal and periodic analytical monitoring for the early detection of secundarisms. Due to the low incidence of secondarisms, all the CPG advocate for monitoring just people at risk or with clinical manifestations. The ESC/EAS guidelines ${ }^{16,17}$ consider the identification of population at risk (advanced age, small body size, female sex, renal and hepatic dysfunction, perioperative periods, hypothyroidism, multisystem disease, and alcohol abuse) as the most important measure for the management of muscular or hepatic damage. The ACC/AHA ${ }^{15}$ guideline consider similar risk factors such as multiple or serious comorbidities including impaired renal or hepatic function, previous statin intolerance or muscle disorders, concomitant use of drugs affecting statin metabolism, history of hemorrhagic stroke, age $>75$ years, and Asian ancestry. The three CPG state that transaminases should be monitored in all patients before starting statins. Referring to CK (creatine kinase), the recommendation of the $\mathrm{ESC} / \mathrm{EAS}^{16,17} \mathrm{CPG}$ is for monitoring in all patients. In contrast, for $\mathrm{ACC} / \mathrm{AHA}^{15}$ and NICE,${ }^{18} \mathrm{CK}$ needs to be monitored before starting statins just in patients with muscular symptoms or at risk for myopathy (personal or family history of statin intolerance or muscle disease, clinical presentation, or concomitant drug therapy that might increase the risk of myopathy). Similar recommendations can be established when considering analytical monitoring during the treatment with statins. For ACC/ AHA, ${ }^{15}$ it is reasonable to measure transaminases and $\mathrm{CK}$ just if symptoms suggesting hepatotoxicity (jaundice) or myotoxicity (pain, tenderness, stiffness, cramping, weakness, or generalized fatigue) arise. After 1 year, it is not necessary to monitor transaminases because in the RCT the hepatotoxicity usually appears during the first 12 months of treatment. For the ESC/EAS, ${ }^{16,17}$ after initiation of statins, $\mathrm{CK}$ determination is not necessary except if the existence of any muscle symptom, but in contrast to the American guidelines, ${ }^{15}$ transaminases should be monitored 8 weeks after the initiation of statin therapy and if the values are lower than three times normal value, once per year after that. The $\mathrm{NICE}^{18}$ recommendation about transaminases is always a basal determination, and then 3 and 12 months after statins have been started. All three CPG recommend three times over normal values for transmaminases and five times for $\mathrm{CK}$ as the analytivcal indicators of damage in liver and muscle to withdrawal statin treatment.

Another aspect about analytical monitoring is that related to lipid profile. It seems that the immediate and logical consequence derived from one of the main points of the controversy established by the new ACC/AHA guideline ${ }^{15}$ about changing the target of treatment ( $\mathrm{CV}$ risk instead of 
analytical parameters) should be that basal and periodical analys of lipid profile are not necessary. But it is not the case, at least from a practical daily perspective, because this CPG, as the European ones, ${ }^{16-18}$ recommends basal and periodic complete lipid profile determinations. All three guidelines establish with a high level of evidence the necessity to determine a complete analytical lipid profile. For the ESC/EAS ${ }^{16,17}$ guidelines, basal lipid profile comprises Tc, Tg, HDLc, LDLc, nHDLc, and the Tc/HDLc ratio. NICE ${ }^{18}$ and $\mathrm{ACC} / \mathrm{AHA}^{15}$ recommend a basal analytical lipid profile including Tc, Tg, HDLc, LDLc, and nHDLc. As a difference with the other two guidelines for NICE fasting sample is not needed. ${ }^{18}$ After statins are started, all the guidelines recommended periodic analytical profiles, although with differences about the time intervals. For the ACC/AHA guideline ${ }^{15}$ analytical lipid profile should be obtained 4-12 weeks after initiation of statin therapy, with controls every 3-12 months as clinically indicated. For the ESC/EAS, ${ }^{16,17}$ the period is 1-12 weeks after pharmacological treatment initiation, 3-4 weeks after pharmacological treatment change, and once per year after objectives are reached. For $\mathrm{NICE}^{18}$ timing for lipid profile determination after hypolipemiant drugs are started is 3 months and after that once per year. The exception is for acute coronary event; in this case the determination should be done 4 weeks after initiation of hypolipemiant treatment. All these recommendations are surprising with regard to the meta-analysis of Perera et al, ${ }^{54}$ which demonstrates that lipid determination once a year is the most predictive as well as effective time period for monitoring.

It is true that, from a conceptual point of view, the final reason for periodic lipid monitoring is quite different among CPG. For the European $\mathrm{CPG}^{16-18}$ periodical analytical determinations are absolutely necessary because analytical parameters are the target. It is not the case for the American $\mathrm{CPG},{ }^{15}$ which recommends analytical monitoring just to be sure that the expected percentage decrease in LDLc compared with the basal values has been achieved and to implement the therapeutic adherence of the patient. Although recognizing the main importance of therapeutic compliance, the ESC/EAS ${ }^{16,17}$ guidelines conclude that "A separate issue is the impact of regular lipid monitoring in promoting patient adherence to lifestyle changes or drug regimens that impact positively on their health, as found in a range of studies. It is unclear if only the process of monitoring is critical in achieving this or a combination of education, regular contact, and adherence assessment." ${ }^{77} \mathrm{NICE}^{18}$ also considers pharmacological adherence as a cornerstone point for the management of $\mathrm{CV}$ risk in general but has not detected any significant and effective specific strategy to increase the adherence to statins treatment.

\section{Aspects to be improved upon in the actual situation of CPG on lipids}

We have seen in this overview that although the new American guideline on dyslipidemia has proposed some different paradigms for the management of dyslipidemia, from a clinical point of view, the impact and consequences are probably not so important, at least not to modify the daily clinical practice, mainly because there are more similarities than dissimilarities. And, when common elements exist, it is possible to find solutions.

In medicine, because of the relative strength of the evidence and constant evolution of knowledge, new points of view should be always welcome as an opportunity to improve. When considering $\mathrm{CPG}$, it is necessary to be brave to recognize the limitations of their recommendations as well as to publically defend new concepts, especially when the new proposals hit against universally established previous ideas ${ }^{68}{ }^{8}$ In this context the main input of the 2013 ACC/AHA guideline ${ }^{15}$ is that with the proposal of new paradigms, the reappraisal by all the medical community regarding some previously untouchable precepts has been activated. It could be criticized for the confusion created among clinicians. However, it could also be interpreted as a call to action in a globalized and technological world among all CPG authors to stop, talk, and discover new ways to identify and overcome the actual gaps. It is necessary to create consensual new clear and global guidelines to be reviewed only when a real novelty has been published with a common, predefined, comparable, and universal methodology and with the capacity to respect local individualities. As medical science is not a question of "yes or no", it is rather always a question of "it seems that" "because of this/these reasons/s."

To help the task of getting a global consensus, we can consider the final conclusions in the text of the three CPG on the management of dyslipidemia considered at the present review as a method for the detection of gaps to be overcome (Table 5). ${ }^{16-18,20}$ With some differences, there are common points to begin to discuss and prioritize strategies. When considering general/methodological necessities, they can be summarized as, 1) need to demonstrate the superiority to treat global CV risk instead of individual CV risk factors, 2) need to demonstrate the beneficial effect of hypolipemiant drugs other than statins, 3) need to obtain evidence from specific RCTs on nonpharmacological treatment of dyslipidemia as well as effectiveness of each kind of treatment. $\mathrm{ESC} / \mathrm{EAS}^{16,17}$ guideline are the only ones to comment about the necessity of a "systematic comparison of current international guidelines to define areas of agreement and the reasons for discrepancies." On the other hand, $\mathrm{NICE}^{18}$ is the only CPG to underscore the need for more information about 
Table 5 Gaps to be solved in the future according to the European and the American clinical practice guidelines on dyslipidemia

\begin{tabular}{|c|c|c|}
\hline ACC/AHA $2013^{14}$ & ESC/EAS $2012^{16,17}$ & NICE $2012^{18}$ \\
\hline \multicolumn{3}{|l|}{ General aspects } \\
\hline $\begin{array}{l}\text { Outcomes of RCTs to evaluate alternative } \\
\text { treatment strategies for ASCVD risk } \\
\text { reduction. These RCTs may compare titration } \\
\text { to specific cholesterol or apolipoprotein goals } \\
\text { versus fixed-dose statin therapy in high-risk } \\
\text { patients. } \\
\text { Outcomes of RCTs of new lipid-modifying } \\
\text { agents to determine the incremental ASCVD } \\
\text { event-reduction benefits when added to } \\
\text { evidence-based statin therapy. } \\
\text { RCTs to determine whether submaximal statin } \\
\text { doses, combined with nonstatin therapies, } \\
\text { reduce ASCVD risk in statin-intolerant } \\
\text { patients. }\end{array}$ & $\begin{array}{l}\text { There are no recent RCTs of a total risk } \\
\text { approach to risk assessment; nor risk } \\
\text { management. } \\
\text { Current systems of grading evidence give most } \\
\text { weight to RCTs, but many lifestyle measures } \\
\text { are less amenable to such assessment than } \\
\text { are drug treatments, which therefore tend to } \\
\text { receive a higher grade. While the GRADE } \\
\text { system attempts to address this issue, more } \\
\text { debate is needed. } \\
\text { A systematic comparison of current } \\
\text { international guidelines is needed to define } \\
\text { areas of agreement and the reasons for } \\
\text { discrepancies. }\end{array}$ & $\begin{array}{l}\text { What is the comparative effectiveness of age } \\
\text { alone and other routinely available risk factors } \\
\text { versus formal structured multifactorial risk } \\
\text { assessment for identifying people at high risk of } \\
\text { developing CVD disease? } \\
\text { When evaluating cost-effectiveness for statin } \\
\text { therapy in reducing CVD, is prediction improved } \\
\text { by the use of a complete meta-analysis dataset } \\
\text { based on individual patient outcomes rather than } \\
\text { published outcomes data from individual trials? } \\
\text { What is the clinical effectiveness and rate of } \\
\text { adverse events of statin therapy using atorvastatir } \\
20 \text { mg per day compared with atorvastatin } 40 \text { mg } \\
\text { per day and atorvastatin } 80 \text { mg per day in people } \\
\text { without established CVD? }\end{array}$ \\
\hline \multicolumn{3}{|l|}{ Specific aspects } \\
\hline $\begin{array}{l}\text { Outcomes of RCTs to evaluate statins or } \\
\text { the primary prevention of ASCVD in adults } \\
>75 \text { years of age. } \\
\text { Evaluation of the incidence, pathophysiology, } \\
\text { clinical course, and clinical outcomes of new- } \\
\text { onset diabetes associated with statin therapy. }\end{array}$ & $\begin{array}{l}\text { The young, women, older people, and ethnic } \\
\text { minorities continue to be underrepresented in } \\
\text { clinical trials. }\end{array}$ & $\begin{array}{l}\text { What is the effectiveness of statin therapy in } \\
\text { older people? } \\
\text { What is the effectiveness of statins or other } \\
\text { treatments that lower low-density lipoprotein- } \\
\text { cholesterol in people with type I diabetes? }\end{array}$ \\
\hline
\end{tabular}

Abbreviations: ACC, American College of Cardiology; AHA, American Heart Association; ASCVD, atherosclerotic cardiovascular disease; EAS, European Atherosclerosis Society; ESC, European Society of Cardiology; NICE, National Institute for Health and Care Excellence; RCT, randomized clinical trial; CVD, cardio vascular disease; ESC/ EAS, European Society of Cardiology.

effectiveness. There is absolute accordance when considering the necessity to obtain more information about benefits in some population subgroups, especially older people, women, and diabetic patients.

In the era of worldwide globalization, it is mandatory to adopt consensual solutions for new modern CPG on dyslipidemia we need to have clinical guidelines that simplify decision-making, based on the best available evidence. Meanwhile the results of large trials like IMPROVE-IT, ${ }^{31}$ PREDIMED, ${ }^{32}$ and more recently HOPE $3^{79}$ can probably help to solve some of the actual gaps. In any case, these and future high-quality RCTs should not be analyzed from an interested point of view creating a war between American and European CPG, because there is no doubt that, although with important limitations, at this moment RCTs generate the most robust evidence. However, it is mandatory to improve the methodology to obtain evidence, and in the actual era where technology is revolutionizing everyday life, a methodological change could be feasible. Most likely, a real shift in the paradigm of medical investigation will be for example the application of big data technology, which in the medium term could allow studies of complete populations instead of reduced samples sometimes with doubtful representation of the reality which needs to be studied. In the immediate-term for clinicians, the advice is to detect and treat patients at risk applying local specific calculators for an early treatment. Considering that the final objective of treating dyslipidemia is to avoid CV events, use of LDLc or nHDLc has to be promoted whatever the intention of the determination, but reinforcing the idea of global CV risk. Probably, it is important to maintain the analytical monitoring of lipid parameters, because clinicians used to work in a daily practice making decisions based on numerical thresholds distinguishing healthy and ill patients. It is very accommodative because it allows a dichotomical, easy, and clear approach to the clinical problems, but we have to remember that, although operative, it is an absolutely artificial approach that creates a false security feeling in the adoption of decisions. In any case, although new approaches are needed for improvement, an indirect indicator that things are being done correctly with the actual strategies is the achieved global reduction in the incidence of worldwide $\mathrm{CV}$ events. ${ }^{78}$

\section{Acknowledgments}

The authors thank Gretchen B Swasey and Marta MolláGonzález for their help with grammatical corrections of the final version of the manuscript. 


\section{Disclosure}

V Giner-Galvañ and V Pallarés-Carratalá have participated in some national, regional, and local formational activities supported by different national pharmaceutical industries (MSD, Pfizer, Novartis, Astra-Zeneca, Amgen) related with dyslipidemia management. The authors report no other conflicts of interest in this work.

\section{References}

1. Murthy L, Shepperd S, Clarke MJ, et al. Interventions to improve the use of systematic reviews in decision-making by health system managers, policy makers and clinicians. Cochrane Database Syst Rev. 2012;9:CD009401.

2. Alderson P. Absence of evidence is not evidence of absence. BMJ. 2004;328(7438):476-477.

3. Rosenberg W, Donald A. Evidence based medicine: an approach to clinical problem-solving. BMJ. 1995;310(6987):1122-1126.

4. Sniderman A, Furberg CD, Toth PP, Thanassoulis G. Is the guideline process replicable and, if not, what does this mean? Prog Cardiovasc Dis. 2015;58(1):3-9.

5. Esposito K, Ceriello A, Genovese S, Giugliano D. Cardiovascular guidelines: separate career may help attenuate controversy. Cardiovasc Diabetol. 2014;13:66.

6. Ferket BS, Colkesen EB, Visser JJ, et al. Systematic review of guidelines on cardiovascular risk assessment: which recommendations should clinicians follow for a cardiovascular health check? Arch Intern Med. 2010;170(1):27-40.

7. Bindslev JB, Schroll J, Gotzsche PC, Lundh A. Underreporting of conflicts of interest in clinical practice guidelines: cross sectional study. BMC Med Ethics. 2013;14:19.

8. Capdevila JA, Gavagnach M, Martínez S, Torres A. Critical evaluation of clinical practice guidelines. Med Clin (Barc). 2008;130(10):376-379.

9. Guallar E, Laine C. Controversy over clinical guidelines: listen to the evidence, not the noise. Ann Intern Med. 2014;160(5):361-362.

10. Isaacs D, Fitzgerald D. Seven alternatives to evidence based medicine. BMJ. 1999;319(7225):1618

11. Barratt A. Evidence based medicine and shared decision making: the challenge of getting both evidence and preferences into health care. Patient Educ Couns. 2008;73(3):407-412.

12. Martin SS, Sperling LS, Blaha MJ, et al. Clinician-patient risk discussion for atherosclerotic cardiovascular disease prevention: importance to implementation of the 2013 ACC/AHA guidelines. J Am Coll Cardiol 2015;65(13):1361-1368.

13. Morris PB, McLain K. What the guidelines do not say: statin non-benefit groups. Curr Atheroscler Rep. 2015;17(1):468.

14. National Cholesterol Education Program (NCEP) Expert Panel on Detection, Evaluation, and Treatment of High Blood Cholesterol in Adults (Adult Treatment Panel III). Third Report of the National Cholesterol Education Program (NCEP) Expert Panel on Detection, Evaluation, and Treatment of High Blood Cholesterol in Adults (Adult Treatment Panel III) final report. Circulation. 2002;106(25):3143-3421.

15. Stone NJ, Robinson JG, Lichtenstein AH, et al; American College of Cardiology/American Heart Association Task Force on Practice Guidelines. 2013 ACC/AHA guideline on the treatment of blood cholesterol to reduce atherosclerotic cardiovascular risk in adults: a report of the American College of Cardiology/American Heart Association Task Force on Practice Guidelines. Circulation. 2014;129(25 Suppl 2): S1-S45.

16. Reiner Z, Catapano AL, De Backer G, et al; European Association for Cardiovascular Prevention \& Rehabilitation, ESC Committee for Practice Guidelines (CPG) 2008-2010 and 2010-2012 Committees. $\mathrm{ESC} / \mathrm{EAS}$ guidelines for the management of dyslipidaemias: the task force for the management of dyslipidaemias of the European Society of Cardiology (ESC) and the European Atherosclerosis Society (EAS). Eur Heart J. 2011;32(14):1769-1818.
17. Perk J, De Backer G, Gohlke H, et al; European Association for Cardiovascular Prevention \& Rehabilitation (EACPR); ESC Committee for Practice Guidelines (CPG). European guidelines on cardiovascular disease prevention in clinical practice (version 2012). The Fifth Joint Task Force of the European Society of Cardiology and Other Societies on Cardiovascular Disease Prevention in Clinical Practice. Eur Heart J. 2012;33(13):1635-1701.

18. Rabar S, Harker M, O’Flynn N, Wierzbicki AS; Guideline Development Group. Lipid modification and cardiovascular risk assessment for the primary and secondary prevention of cardiovascular disease: summary of updated NICE guidance. BMJ. 2014;349:g4356.

19. Goff DC Jr, Lloyd-Jones DM, Bennett G, et al. 2013 ACC/AHA guideline on the assessment of cardiovascular risk: a report of the American College of Cardiology/American Heart Association Task Force on practice guidelines. Circulation. 2014;129(25 Suppl 2): S49-S73.

20. Phillips E, Saseen JJ. Current controversies with recent cholesterol treatment guidelines. J Pharm Pract. 2016;29(1):15-25.

21. Finkel JB, Duffy D. 2013 ACC/AHA cholesterol treatment guideline: paradigm shifts in managing atherosclerotic cardiovascular disease risk. Trends Cardiovasc Med. 2015;25(4):340-347.

22. Flink L, Underberg JA, Newman JD, Gianos E. The recent national lipid association recommendations: how do they compare to other established dyslipidemia guidelines? Curr Atheroscler Rep. 2015;17(4):494.

23. Saraf S, Ray KK. Guidelines in the USA, a viewpoint contrary to those guidelines in Europe, Canada, Britain and the International Atherosclerosis Society. Curr Opin Lipidol. 2014;25(6):413-417.

24. Ray KK, Kastelein JJP, Boekholdt SM, et al. The ACC/AHA 2013 guideline on the treatment of blood cholesterol to reduce atherosclerotic cardiovascular disease risk in adults: the good the bad and the uncertain: a comparison with ESC/EAS guidelines for the management of dyslipidaemias 2011. Eur Heart J. 2014;35(15):960-968.

25. Martin SS, Abd TT, Jones SR, Michos ED, Blumenthal RS, Blaha MJ. 2013 ACC/AHA cholesterol treatment guideline: what was done well and what could be done better. J Am Coll Cardiol. 2014;63(24): 2674-2678.

26. Lobos M, Galve E, Royo-Bordonada MÁ, et al; Spanish Interdisciplinary Committee for Cardiovascular Disease Prevention; Spanish Society of Cardiology. Spanish Interdisciplinary Committee for Cardiovascular Disease Prevention and the Spanish Society of Cardiology position statement on dyslipidemia management. Differences between the European and American guidelines. Rev Esp Cardiol (Engl Ed). 2014;67(11):913-919.

27. López-Jiménez F, Simha V, Thomas RJ, et al. A summary and critical assessment of the 2013 ACC/AHA guideline on the treatment of blood cholesterol to reduce atherosclerotic cardiovascular disease risk in adults: filling the gaps. Mayo Clin Proc. 2014;89(9):1257-1278.

28. Steinbrook R. Guidance for guidelines. N Engl J Med. 2007;356(4): 331-333.

29. Expert Dyslipidemia Panel of the International Atherosclerosis Society Panel members. An International Atherosclerosis Society Position Paper: global recommendations for the management of dyslipidemia. Full report. J Clin Lipidol. 2014;8(1):29-60.

30. Ades PA. A controversial step forward: a commentary on the 2013 ACC/AHA guideline on the treatment of blood cholesterol to reduce atherosclerotic cardiovascular risk in adults. Coron Artery Dis. 2014;25(4):360-363.

31. Cannon CP, Blazing MA, Giugliano RP, et al; IMPROVE-IT Investigators. Ezetimibe added to statin therapy after acute coronary syndromes. N Engl J Med. 2015;372(25):2387-2397.

32. Martínez-González MA, Salas-Salvadó J, Estruch R, et al; PREDIMED investigators. Benefits of the mediterranean diet: insights from the PREDIMED study. Prog Cardiovasc Dis. 2015;58(1): $50-60$.

33. Guyatt GH, Oxman AD, Vist GE, et al. GRADE: an emerging consensus on rating quality of evidence strength of recommendations. $B M J$ 2008;336(7650):924-926. 
34. Preiss D, Kristensen SL. The new pooled cohort equations risk calculator. Can J Cardiol. 2015;31(5):613-619.

35. D'Agostino RB, Vasan RS, Pencina MJ, et al. General cardiovascular risk profile for use in primary care: the Framingham Heart Study. Circulation. 2008;117(6):743-753.

36. Conroy R, Pyorala K, Fitzgerald AP, et al. Estimation of ten-year risk of fatal cardiovascular disease in Europe: the SCORE project. Eur Heart J. 2003;24(11):987-1003.

37. Hippisley-Cox J, Coupland C, Vinogradova Y, et al. Predicting cardiovascular risk in England and Wales: prospective derivation and validation of QRISK2. BMJ. 2008;336(7659):1475-1482.

38. Hippisley-Cox J, Coupland C, Robson J, Brindle P. Derivation, validation, and evaluation of a new QRISK model to estimate lifetime risk of cardiovascular disease: cohort study using QResearch database. BMJ. 2010;341:c6624.

39. Woodward M, Brindle P, Tunstall-Pedoe H; SIGN group on risk estimation. Adding social deprivation and family history to cardiovascular risk assessment: the ASSIGN score from the Scottish Heart Health Extended Cohort (SHHEC). Heart. 2007;93(2):172-176.

40. Lloyd-Jones DM, Leip EP, Larson MG, et al. Prediction of lifetime risk for cardiovascular disease by risk factor burden at 50 years of age. Circulation. 2006;113(6):791-798.

41. Assmann G, Cullen P, Schulte H. Simple scoring scheme for calculating the risk of acute coronary events based on the 10-year follow-up of the Prospective Cardiovascular Munster (PROCAM) study. Circulation. 2002;105(3):310-315.

42. Woodward M, Brindle P, Tunstall-Pedoe H. Adding social deprivation and family history to cardiovascular risk assessment: the ASSIGN score from the Scottish Heart Health Extended Cohort (SHHEC). Heart. 2007;93(2):172-176.

43. Cullen P, Assmann G. Primary and secondary prevention of coronary heart disease. A position paper of the International Task Force for the Prevention of Coronary Heart Disease. Dtsch Med Wochenschr. 2000;125(28-29):881-887.

44. Cooney MT, Dudina AL, Graham IM. Value and limitations of existing scores for the assessment of cardiovascular risk: a review for clinicians. J Am Coll Cardiol. 2009;54(14):1209-1227.

45. Ridker PM, Cook NR. Statins: new American guidelines for prevention of cardiovascular disease. Lancet. 2013;382(9907):1762-1765.

46. Pencina MJ, Navar-Boggan AM, D'Agostino RB, et al. Application of new cholesterol guidelines to a population-based sample. $N$ Engl $J$ Med. 2014;370:1422-1431.

47. Kavousi M, Leening MJ, Nanchen D, et al. Comparison of application of the ACC/AHA guidelines, Adult Treatment Panel III guidelines, and European Society of Cardiology guidelines for cardiovascular disease prevention in a European cohort. JAMA. 2014;311(14):1416-1423.

48. Marshall TM. New insights into the statin-cholesterol controversy. J Am Phy Surg. 2014;19(2):42-46.

49. Yeboah J, Polonsky TS, Young R, et al. Utility of non traditional risk markers in individuals ineligible for statin therapy according to the 2013 American College of Cardiology/American Heart Association Cholesterol Guidelines. Circulation. 2015;132(10):916-922.

50. Cholesterol Treatment Trialists' (CTT) Collaboration, Baigent C, Blackwell L, Emberson J, et al. Efficacy and safety of more intensive lowering of LDL cholesterol: a meta-analysis of data from 170,000 participants in 26 randomised trials. Lancet. 2010;376(9753):1670-1681.

51. Cholesterol Treatment Trialists' (CTT) Collaborators, Mihaylova B, Emberson J, Blackwell L, et al. The effects of lowering LDL cholesterol with statin therapy in people at low risk of vascular disease: meta-analysis of individual data from 27 randomised trials. Lancet. 2012;380(9841):581-590.

52. Smith SC Jr, Grundy SM. 2013 ACC/AHA guideline recommends fixed-dose strategies instead of targeted goals to lower blood cholesterol. J Am Coll Cardiol. 2014;64(6):601-612.

53. Müller-Wieland D, Assmann G, Carmena R, et al. Treat-to-target versus dose-adapted statin treatment of cholesterol to reduce cardiovascular risk. Eur J Prev Cardiol. 2016;23(3):275-281.
54. Perera R, McFadden E, McLellan J, et al. Optimal strategies for monitoring lipid levels in patients at risk or with cardiovascular disease. A systematic review with statistical and cost-effectiveness modelling. Health Technol Assess. 2015;19(100):1-402.

55. Davignon J. Beneficial cardiovascular pleiotropic effects of statins. Circulation. 2004;109(Suppl 1):III39-III43.

56. Hayward RA, Krumholz HM. Three reasons to abandon low-density lipoprotein targets: an open letter to the Adult Treatment Panel IV of the National Institutes of Health. Circ Cardiovasc Qual Outcomes. 2012; $5(1): 2-5$.

57. Hayward RA, Hofer TP, Vijan S. Narrative review: lack of evidence for recommended low-density lipoprotein treatment targets: a solvable problem. Ann Intern Med. 2006;145(7):520-530.

58. Jarcho JA, Keaney JF Jr. Proof that lower is better. LDL Cholesterol and IMPROVE-IT. $N$ Engl J Med. 2015;372(25):2448-2450.

59. Heart Protection Study Collaborative Group. MRC/BHF Heart Protection Study of cholesterol lowering with simvastatin in 20.536 high-risk individuals: a randomized placebo-controlled trial. Lancet. 2002;360(9326):7-22.

60. Pintó X, García-Gómez MC. New agents for hypercholesterolemia. Med Cli (Barc). 2016;146(4):172-177.

61. Aguiar C, Alegría E, Bonadonna RC, et al. A review of the evidence on reducing macrovascular risk in patients with atherogenic dyslipidaemia: a report from an expert consensus meeting on the role of fenofibrate statin combination therapy. Atheroscler Suppl. 2015;19: $1-12$.

62. Rossebø AB, Pedersen TR, Boman K, et al; SEAS Investigators. Intensive lipid lowering with simvastatin and ezetimibe in aortic stenosis. N Engl J Med. 2008;359(13):1343-1356.

63. Baigent C, Landray MJ, Reith C, et al; SHARP Investigators. The effects of lowering LDL cholesterol with simvastatin plus ezetimibe in patients with chronic kidney disease (Study of Heart and Renal Protection): a randomised placebo-controlled trial. Lancet. 2011;377(9784): 2181-2192.

64. FDA Briefing Document. Endocrinologic and Metabolic Drugs Advisory Committee (EMDAC) December 14, 2015. Available from: http:// www.fda.gov/downloads/AdvisoryCommittees/CommitteesMeeting Materials/Drugs/EndocrinologicandMetabolicDrugsAdvisoryCommit tee/UCM476505.pdf. Accessed Dec 10, 2015.

65. Krumholz HM. Emphasizing the burden of proof: The American College of Cardiology 2008 Expert Panel Comments on the ENHANCE Trial. Circ Cardiovasc Qual Outcomes. 2010;3(6):565-567.

66. Robins SJ, Collins D, Wittes JT, et al; VA-HIT Study Group. Veterans Affairs High-Density Lipoprotein Intervention Trial. Relation of gemfibrozil treatment and lipid levels with major coronary events: VA-HIT: a randomized controlled trial. JAMA. 2001;285(12):1585-1591.

67. National Institute for Health and Clinical Excellence. Ezetimibe for the treatment of primary (heterozygous-familial and non-familial) hypercholesterolaemia. NICE technology appraisal guidance 132. London: National Institute for Health and Clinical Excellence; 2007. Available from: http://guidance.nice.org.uk/TA132/Guidance/pdf/English. Accessed Dec 10, 2015.

68. Krumholz HM. A note to my younger colleagues... be brave. Circ Cardiovasc Qual Outcomes. 2012;5(3):245-246.

69. Jackson R, Lawes CM, Bennett DA, Milne RJ, Rodgers A. Treatment with drugs to lower blood pressure and blood cholesterol based on an individual's absolute cardiovascular risk. Lancet. 2005; 365(9457):434-441.

70. Blood Pressure Lowering Treatment Trialists' Collaboration; Sundström J, Arima H, Woodward M, et al. Blood pressure-lowering treatment based on cardiovascular risk: a meta-analysis of individual patient data. Lancet.2014;384(9943):591-598.

71. Raccah D. Importance of blood glucose management in the multifactorial approach of absolute cardiovascular risk in type 2 diabetes: the lessons from the Steno 2 study. Diabetes Metab. 2006;32(Spec 2): 2S48-2S51. 
72. Weng TC, Yang YH, Lin SJ, Tai SH. A systematic review and metaanalysis on the therapeutic equivalence of statins. J Clin Pharm Ther 2010;35(2):139-151.

73. Mukhtar RY, Reid J, Reckless JP. Pitavastatin. Int J Clin Pract. 2005; 59(2):239-252.

74. Law MR, Wald NJ, Rudnicka AR. Quantifying effect of statins on low density lipoprotein cholesterol, ischaemic heart disease, and stroke: systematic review and meta-analysis. BMJ. 2003;326(7404):1423.

75. McKenney JM, Davidson MH, Jacobson TA, Guyton JR; National Lipid Association Statin Safety Assessment Task Force. Final conclusions and recommendations of the National Lipid Association Statin Safety Assessment Task Force. Am J Cardiol. 2006;97(8A):89C-95C.
76. Sattar N, Preiss D, Murray HM, et al. Statins and risk of incident diabetes: a collaborative meta-analysis of randomized statin trials. Lancet. 2010;375(9716):735-742.

77. Coodley GO, Jorgensen M, Kirschenbaum J, et al. Lowering LDL cholesterol in adults: a prospective, community-based practice initiative. Am J Med. 2008;121(7):604-610.

78. Mendis S, Puska P, Norrving B, et al. Global Atlas on Cardiovascular Disease Prevention and Control. Geneva: World Health Organization in collaboration with the World Heart Federation and the World Stroke Organization; 2011.

79. Cushman WC, Goff DC. More HOPE for prevention with statin. NEngl J Med. Epub 2016 Apr 2. 2016;374(21):2085-2087.
Vascular Health and Risk Management

\section{Publish your work in this journal}

Vascular Health and Risk Management is an international, peerreviewed journal of therapeutics and risk management, focusing on concise rapid reporting of clinical studies on the processes involved in the maintenance of vascular health; the monitoring, prevention and treatment of vascular disease and its sequelae; and the involvement of

\section{Dovepress}

metabolic disorders, particularly diabetes. This journal is indexed on PubMed Central and MedLine. The manuscript management system is completely online and includes a very quick and fair peer-review system, which is all easy to use. Visit http://www.dovepress.com/ testimonials.php to read real quotes from published authors.

Submit your manuscript here: https://www.dovepress.com/vascular-health-and-risk-management-journal 